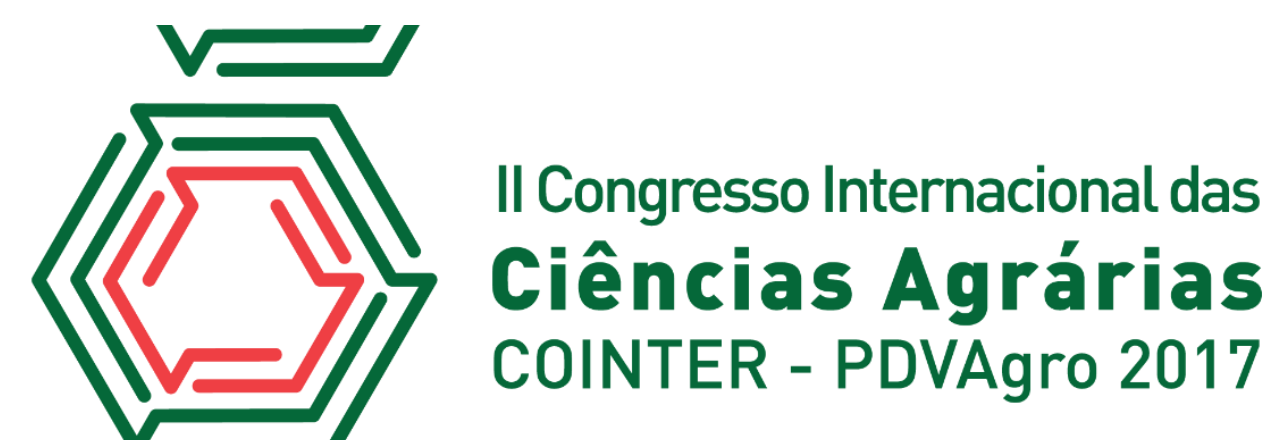

\title{
CONSTRUÇÃO DE UMA GLOSSÁRIO DE SINAIS DE TERMOS UTILIZADOS NO ENSINO DA QUÍMICA \\ Apresentação: Comunicação Oral
}

Regina de Fátima Freire Valentim Monteiro'; Layce Alicy Cunha Alves Pontes ${ }^{2}$

\begin{abstract}
Resumo
A construção do Glossário de Libras: Química foi realizado e fomentado pelo Programa Gestão Sustentável do IFPB - Campus João Pessoa. Baseado no reconhecimento da LIBRAS - Língua Brasileira de Sinais, como língua de comunicação da comunidade surda brasileira, através da Lei $\mathrm{n}^{\circ}$ 10.436, de 24 de abril de 2002. O projeto surgiu durante a tradução de materiais didáticos para Libras dentre eles, especificamos o material didático da disciplina de Química, bem assim, da inquietação dos estudantes do cursos de Licenciatura em Química sobre a escassez de sinais para os termos utilizados no ensino de Química. O estudo visa colaborar com o processo de escolarização das Pessoas Surdas ampliando o léxico nesta área específica do conhecimento, favorecendo um melhor serviço de tradução e interpretação pelos TILS $^{3}$, que atuam na tradução deste componente curricular. Trabalharam no projeto: estudantes surdos fluentes na Libras, TILS estudantes do curso de Licenciatura em Química e professores de Libras Instituto Federal de Educação, Ciência e Tecnologia da Paraíba- IFPB e da Universidade Federal da Paraíba - UFPB. Após pesquisa de levantamento em diferentes fontes, inclusive no próprio Campus do IFPB, foram catalogados 146 sinais considerados coerentes conceitualmente e visualmente com os termos, utilizados no ensino da Química. Foram construídas propostas de sinais para alguns termos que não identificamos um sinal correspondente em Libras. O desenvolvimento do projeto deixou evidente a necessidade e preenchimento de uma lacuna lexical nesta área, e, a participação de profissionais conhecedores da Química, docentes e licenciandos e, da Libras, professores, tradutores intérpretes da Libras e estudantes surdos e seus usuários, como uma medida de cuidado para alcançar a finalidade de garantir a coerência conceitual e visual aos sinais, que serão propostos para o desenvolvimento dos estudantes Surdos sem comprometer sua aprendizagem.
\end{abstract}

Palavras-Chave: EDUCAÇÃO, LEXICOLOGIA, LIBRAS, QUÍMICA.

\footnotetext{
${ }^{1}$ Professora de Libras da Coordenação de Códigos, Linguagem e suas Tecnologias, especialista em Libras (SOCIESC) e Educação Inclusiva (UNIPÊ), Instituto Federal de Educação, Ciência e Tecnologia da Paraíba- IFPB, regina.monteiro@ifpb.edu.br

${ }^{2}$ Licenciatura em Química, Instituto Federal de Educação, Ciência e Tecnologia da Paraíba- IFPB, alicypontes@hotmail.com

${ }^{3}$ Tradutor e Intérprete de Língua Brasileira de Sinais, reconhecido pela Lei no 12.319, de 1ㅇde setembro de 2010.
} 


\section{Introdução}

O Projeto Glossário de Libras: Química foi motivado pelo desejo inicial de salvaguardar os sinais utilizados no ensino da Química pelos estudantes surdos e Tradutores e Intérpretes da Língua de Sinais -TILS, como também, os sinais encontrados em materiais impressos e digitais (dicionários, glossários, artigos, vídeos etc.), para compilação e posterior divulgação, colaborando assim com o processo de difusão dos sinais específicos utilizados no ensino da Química. Outrossim, foi elaborada uma lista de termos ainda sem sinal correspondente, tomando-se como base o livro "Química na abordagem do cotidiano: Química geral e Inorgânica" de PERUZZO e CANTO (2006), que posteriormente alguns receberam sugestão de sinal para os referidos sinais. Objetivando gerar melhorias na qualidade do acesso a informação das pessoas Surdas mediante o preenchimento das lacunas lexicais. Por meio da disponibilização aos TILS dos sinais catalogados.

Durante o desenvolvimento, o projeto foi enriquecido com a participação da professora Rosilene Silva Marinho da Universidade Federal da Paraíba - UFPB, que lançou um olhar como pesquisadora do processo lexicográfico sobre as etapas de construção de sinais recém propostos, para termos que ainda não possuíam um equivalente, como objeto de sua pesquisa de mestrado.

Possibilitando a realização da análise da constituição dos sinais criados, tendo como base, a premissa de aspectos linguísticos da Libras, aspecto conceitual e contextual do emprego dos termos aplicados no ensino da Química.

\section{Fundamentação Teórica}

O processo de dicionarização das línguas de sinais apresenta obras com objetivos distintos, mas todos com um aspecto comum: o registro da língua. É possível encontrar obras em que o acervo lexical é simplesmente registrado para fins de divulgação da língua, que era o principal objetivo dos primeiros dicionários. Eles contribuem para a manutenção e revitalização das línguas, uma vez que permitem às comunidades de falantes, utilizá-los como banco de dados, por isso, servem como fontes de registro e descrição das línguas.

A dicionarização das línguas de sinais revela uma evolução metodológica em relação aos processos lexicográficos, possibilitando a descrição e documentação dos padrões linguísticos, além da elaboração de um banco de dados que permite aos profissionais observarem os aspectos fonéticofonológicos e até semânticos-pragmáticos.

A incorporação da Língua de Sinais aos projetos educacionais para surdos está relacionada à compreensão da especificidade linguística, cognitiva e sociocultural da Pessoa Surda, como também à garantia dos direitos civis. Isso surge em resposta à necessidade de adaptações do contexto educacional, que ao inserir o aluno surdo, deve garantir a acessibilidade linguística por meio da 
interpretação e da difusão da Libras.

"A oferta atual de educação para os surdos aponta na direção de uma proposta pedagógica bilíngue, em que são ressaltadas a importância e a necessidade da aquisição da língua de sinais para a consecução da aprendizagem da língua portuguesa." (SEESP/MEC, 2005 apud MARINHO, 2007, p. 26).

O aluno Surdo, enquanto usuário da Libras, tem acesso a informações como conhecimento escolar, escrita do português e a cultura dos ouvintes, através do serviço de tradução, favorecendo seu desenvolvimento como indivíduo Surdo, exercendo assim, parte das ações necessárias à inclusão social.

Sendo fundamental a difusão da Libras como instrumento de contribuição para a interação dos alunos Surdos com os demais participantes da comunidade escolar, visto que a falta de conhecimento da língua de sinais muitas vezes, torna-se uma barreira comunicativa, prejudicando o estabelecimento de vínculos na instituição. Sabemos que a construção de uma proposta bilíngue possui ações que convergem principalmente para as línguas envolvidas: o Português e a LIBRAS.

Visando isso, contemplamos com este projeto três pontos da educação bilíngue: o serviço de tradução/interpretação, o registro e a difusão de sinais específicos de química.

\subsubsection{O Tradutor Intérprete da Língua Brasileira de Sinais - TILS}

O intérprete de língua de sinais é descrito como "a pessoa que interpreta de uma dada língua de sinais para outra língua, ou desta outra língua para uma determinada língua de sinais" (QUADROS, 2003 apud MARINHO, 2007, p.27). O profissional se responsabiliza por interpretar todas as informações que são ministradas pelo professor e demais materiais didáticos.

Em sala de aula, o TILS deve atuar com competência a transmissão de diferentes conteúdos e graus de complexidade. O conteúdo científico possui termos com significados específicos às ciências da natureza que englobam: biologia, física e química, tornam-se matérias difíceis para o TILS cumprir a competência exigida. Decorrente disso, quando o intérprete reconhece que a interpretação dos termos tende a confundir o aluno, esse profissional pode utilizar outros recursos, como por exemplo, a datilologia. MARINHO (2007) determina três pontos negativos com vista a este recurso:

"Os recursos mais empregados são: a datilologia, a indicação de termos no quadro negro e a apresentação de ilustrações. O primeiro recurso não é bem quisto por três razões: (i) a rapidez da soletração impede muitas vezes o reconhecimento da palavra pelo surdo; (ii) muitos termos são de origem grega ou latina e, neste caso, é comum o intérprete digitar letras erradas por desconhecimento da grafia português; 
(iii) a forma sem acesso à substância dificulta a formação de conceitos. " (MARINHO, 2007, p. 33).

A ausência de glossário com os termos específicos das matérias aplicadas na sala de aula ou materiais didáticos, é outra dificuldade enfrentada por alunos Surdos e TILS, o desconhecimento dos termos encontrados nos livros, seu conceito e contextualização na área do conhecimento estudada.

Alguns sinalários ${ }^{4}$ com termos utilizados na Química, são encontrados, mas ainda com uma quantidade insuficiente para atender à correlação linguística e competência referencial necessárias ao processo de tradução. Indicando a necessidade urgente na produção de glossários de LIBRAS para áreas específicas a fim de registrar signos linguísticos adequados aos conceitos explorados pelas diversas áreas de estudo subsidiando a tradução/interpretação dos conteúdos.

\subsubsection{Sinais específicos de química: registro e a difusão.}

A evolução da língua atende as mais diversas situações comunicativa, sendo ela um sistema em constante relação com o contexto e comunidade de falantes. Saussure (2002) afirma que a língua é social, isso significa que a língua não constitui um conhecimento autônomo, independente do comportamento.

O léxico tem papel fundamental nas relações comunicativas, porque é nele que encontramos o vocabulário. Tão importante para as relações estabelecidas entre os usuários de uma língua. Tomando como premissa que a língua é social, estudar o léxico de uma língua é uma ação indissociável do estudo da história da comunidade linguística dela pertencente. Os hábitos e aspectos culturais são refletidos na língua. COSTA (2012, p.56) alerta sobre a motivação para termos específicos:

É preciso verificar as situações e os contextos em que são produzidos os significados e reconhecê-los dentro do campo lexical, com a percepção da ideologia que gera a formação de sinais e palavras - essa metodologia é possível, conforme as principais teorias sobre o assunto.

Os signos linguísticos são regidos por preceitos de formação e derivação dos sinais, a produtividade de tais regras, as restrições, a motivação do signo linguístico. Considerando a complexidade dos termos específicos de química, a lexicografia analisa as relações linguísticas, fonológicas, morfossintáticas, pragmáticas, históricas e culturais.

\footnotetext{
${ }^{4}$ Para Stumpf (2005), sinalário é o conjunto de expressões que compõem o léxico de uma determinada língua de sinais.
} 


\section{Metodologia}

Este trabalho foi realizado no IFPB - campus João Pessoa - 2014-2015, baseia-se em uma pesquisa de cunho qualitativo, de caráter exploratório, por meio de uma pesquisa bibliográfica. Inicialmente foi realizado um levantamento de termos utilizados no ensino da Química no $1^{\circ}$ ano do Ensino Técnico Integrado ao Médio - ETIM, tomando como referência o livro de "Química na abordagem do cotidiano: Química geral e Inorgânica" de PERUZZO e CANTO (2006), que deu origem a uma lista de 80 termos dos quais 57 termos possuíam sinal correspondente em Libras.

Em seguida foi realizado uma busca por fontes de dados para verificação de sinais existentes de termos utilizados no ensino da Química disponibilizados em dicionários, catalogados, apostila empregada em sala de aula no curso de Licenciatura em Química do IFPB, artigos, vídeos disponibilizados no web e site, sendo computadas seis (6) fontes de registros de sinais totalizando uma lista de 180 sinais de termos. Após uma a análise preliminar, baseada em aspectos conceituais/contexto e visuais de alguns sinais que foram considerados inadequados.

Realizando posteriormente a compilação de 157 sinais dos termos encontrados e considerados inicialmente adequados, um termo por tabela, como seus respectivos sinais e análise comparativa entre os mesmos, considerando aspectos linguísticos da Libras no campo de motivação da criação dos sinais e aspectos conceituais e contextuais dos termos em questão. 


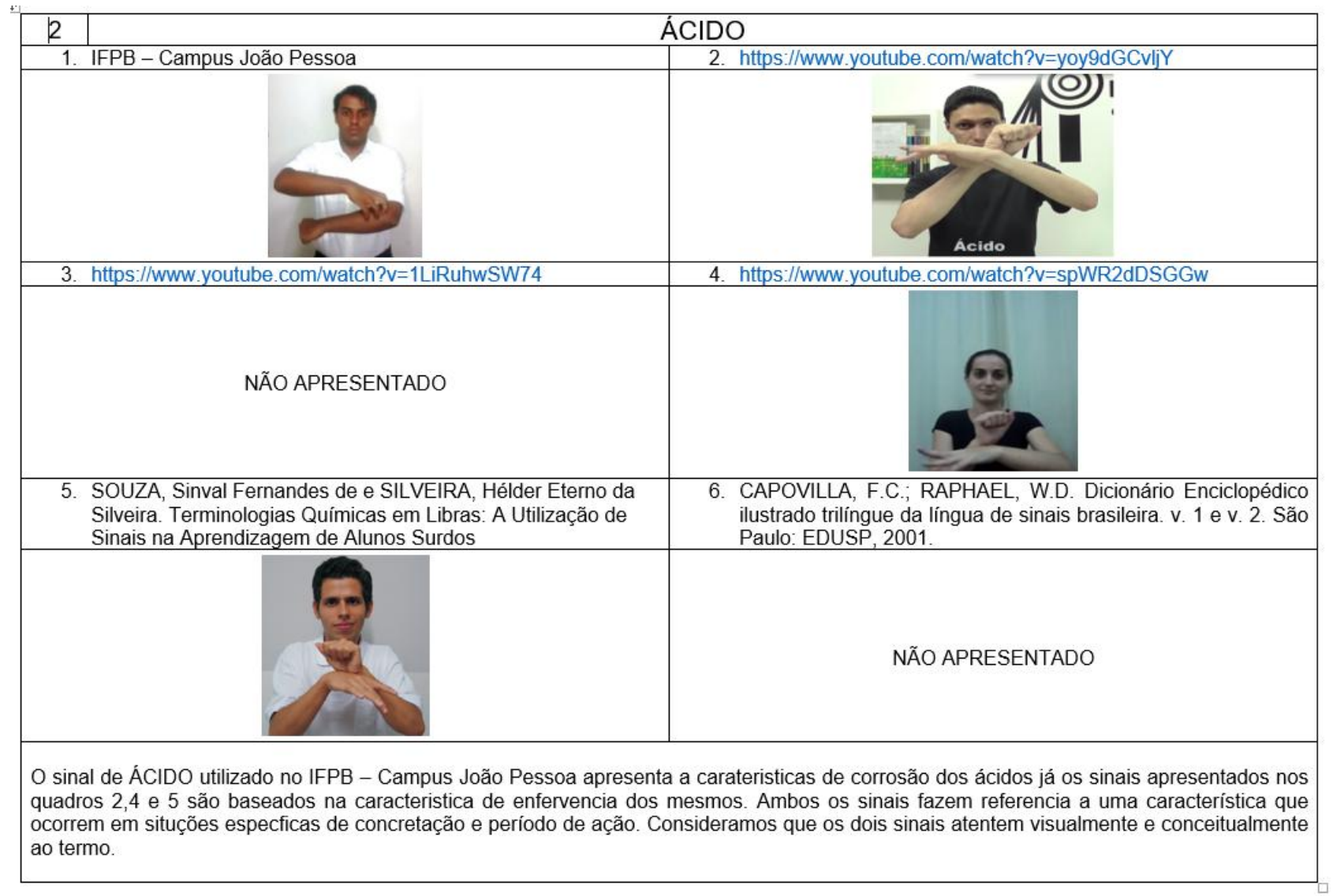

Depois de várias propostas de tabela de compilação e análise dos sinais para o termos, chegamos ao modelo acima apresentado que permite a visualização das seis (6) fontes de sinais e a descrição de uma breve análise entre as características dos sinais encontrados para o termo.

Posteriormente, a equipe formada por estudantes de cursos técnicos - surdos, e ensino superior de Licenciatura em Química, TILS e professores de Libras do IFPB e da UFPB, dentre eles um surdo, avaliaram os termos utilizados no ensino da Química.

A avaliação dos sinais para os termos foi realizada pela equipe e convidados da comunidade surda de João Pessoa, tendo em vista sua relação com o conceito do termo e representação visual do mesmo. Durante o processo foram montados slides com o conceito do termo e imagens que representassem, ilustrassem ou remetesse ao mesmo.

Imagem 2: Slide utilizado da avaliação dos sinais. Fonte: Própria 


\section{LABORATÓRIO: Locais utilizados para exercer as práticas experimentais.}

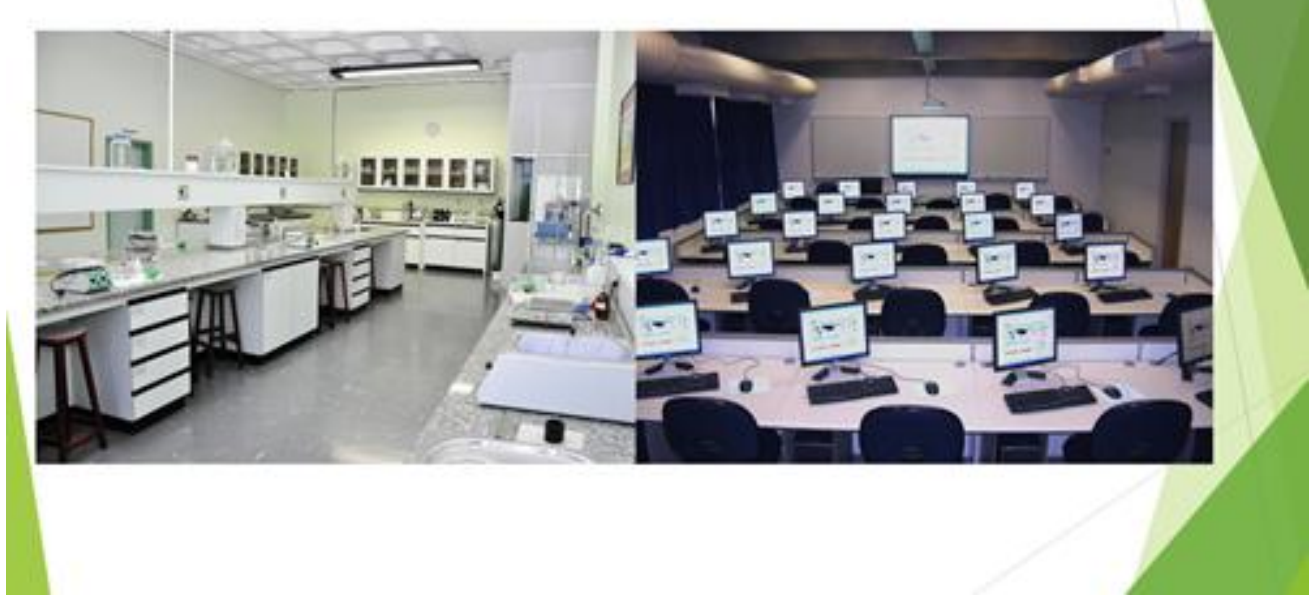

A apresentação dos slides foi acompanhada da apresentação do sinal ou sinais encontrados seguidos da argumentação e considerações. Concluímos o processo com a gravação de 146 vídeos pelo professor Ewerton de Lima Silva da UFPB, processo enriquecido pela experiência visual do professor, por ser uma pessoa Surda usuária de LIBRAS. Estamos em processo de finalização para a publicação do Glossário pela Editora do IFPB, em formato digital.

\section{Resultados e Discussão}

O estudo possibilitou o reconhecimento da relevância de projetos de inicialmente registrar e divulgar os sinais na área específica da Química, e a necessidade de apresentação de propostas de sinais para a comunidade surda de sinais adequados visualmente ao conceito e contexto do emprego do termo. O quadro abaixo demonstra a quantidade de sinais apresentados por fonte pesquisa.

Quadro 1: Demonstrativo do número de sinais por fonte pesquisada. Fonte: Própria

\begin{tabular}{|l|c|}
\hline FONTES DA PESQUISA & NÚMERO DE SINAIS \\
\hline IFPB (consulta aos estudantes e intérpretes) & 157 \\
\hline Instituto PHALA - Centro de desenvolvimento para surdos & 13 \\
\hline Instituto Federal Fluminense - IFF, campus Cabo Frio. & 11 \\
\hline UNEC - Centro Universitário de Caratinga. & 36 \\
\hline
\end{tabular}




\begin{tabular}{|l|c|}
\hline $\begin{array}{l}\text { Terminologias Químicas em Libras: A Utilização de Sinais na } \\
\text { Aprendizagem de Alunos Surdos. }\end{array}$ & 23 \\
\hline Dicionário Enciclopédico ilustrado trilíngue da língua de sinais brasileira. $^{6}$ & 37 \\
\hline
\end{tabular}

O quadro sinaliza que embora existam algumas iniciativas, o número de sinais é pequeno e, consequentemente, não atende a amplitude do campo lexical específico da Química. Além da quantidade de sinais, o que nos preocupa e a apresentação e utilização de sinais que podem comprometer a compreensão da pessoa surda sobre os conteúdos da Química, porque apresentam divergência conceitual, como o apresentado no quadro abaixo.

$\mathrm{Na}$ imagem 3 podemos observar que o sinal para ELÉTRON é realizado por 3 fontes, igualmente, como os mesmos parâmetros do sinal para ELETRICIDADE, isso pode ser considerado uma polissemia. Considerando que a corrente é o movimento ordenado de "elétrons", e que as substâncias não possuem esta condição de condutividade. Consideramos que este sinal, pode apresentar comprometimento conceitual. Por sua vez, os sinais apresentados para ÁCIDO, na imagem 1, embora diferentes estruturalmente na constituição do sinal, cada um apresenta uma característica inerente aos "ácidos", corrosão e efervescência, respectivamente sinalizados no IFPB e nas outras 3 fontes, não se distanciam conceitualmente e nem visualmente da ideia de "ácido".

Imagem 3: Quadro de termo com sinais para ELÉTRON. Fonte: Própria

\footnotetext{
${ }^{5}$ SOUZA, Sinval Fernandes de e SILVEIRA, Hélder Eterno da Silveira. Terminologias Químicas em Libras: A Utilização de Sinais na Aprendizagem de Alunos Surdos.

${ }^{6}$ CAPOVILLA, F.C.; RAPHAEL, W.D. Dicionário Enciclopédico ilustrado trilíngue da língua de sinais brasileira. v. 1 e v. 2. São Paulo: EDUSP, 2001.
} 


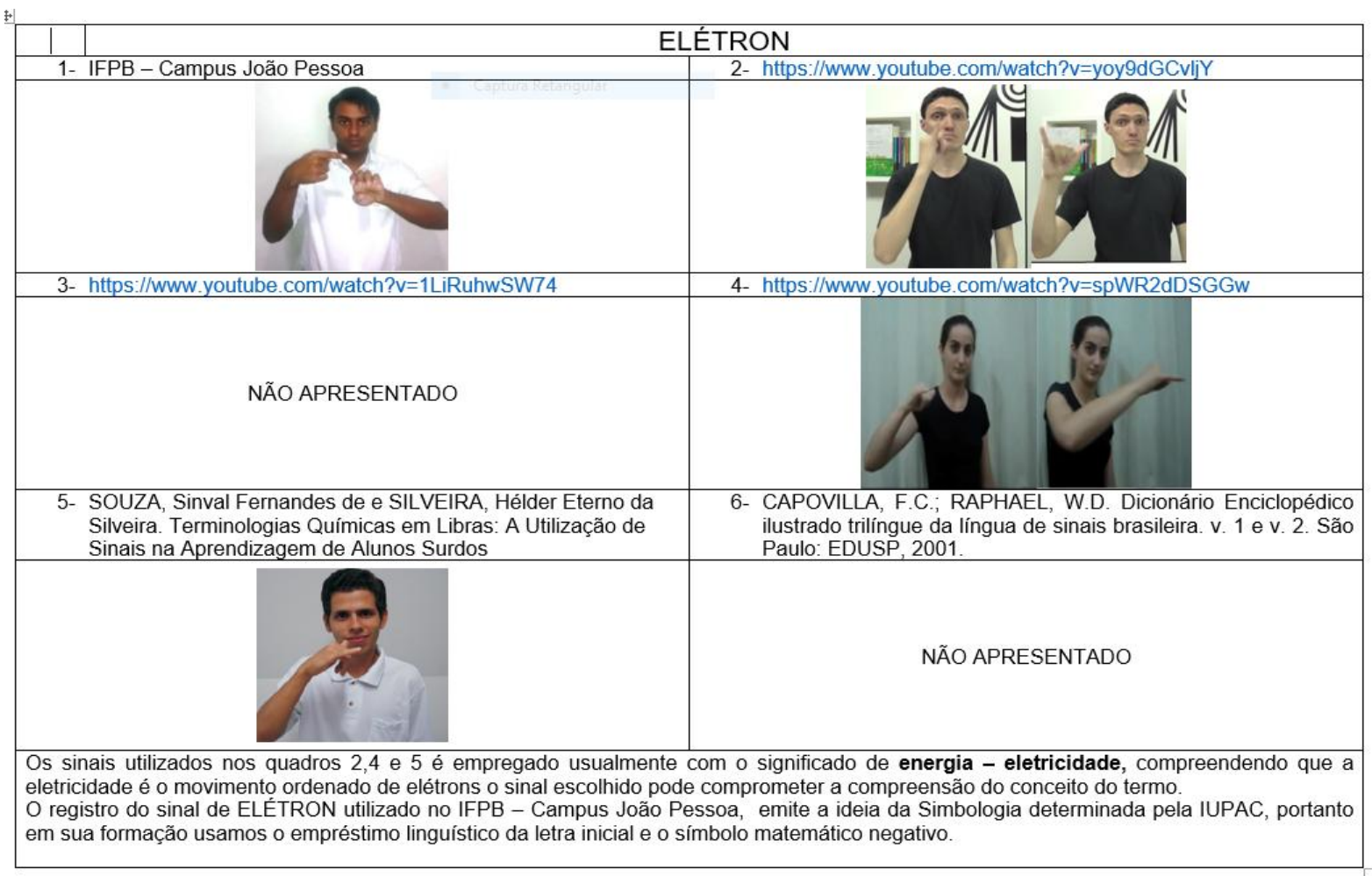

\section{Conclusões}

Durante o desenvolvimento do projeto adquirimos a compreensão da importância e complexidade do processo de criação de sinais para termos de áreas específicas do conhecimento, no caso particular da Química. Escolhas de estruturas de sinais inadequados visualmente ao conceito/contexto da aplicação dos termos, coloca em risco a compreensão do conteúdo apresentado para a pessoa surda. O número de termos utilizados no ensino da Química em suas diferentes áreas: orgânica, inorgânica, analítica, físico-química etc, ainda sem sinais em Libras é considerável. Com o projeto, registramos 146 vídeos, a salvaguarda destes sinais ainda não é o suficiente para promover o acesso ao conhecimento mais profundo da Química. A divulgação dos sinais já gravados, análise e promoção de situações de criação de sinais para termos ainda sem seus correspondentes é necessário para a assegurar o direito à Educação sem comprometer sua qualidade. Direcionando os estudos para a utilização de sinais coerentes conceitualmente e visualmente aos termos utilizados no ensino da Química e uma possível padronização, assim como ocorre com os termos para os ouvintes com a União Internacional de Química Pura e Aplicada - IUPAC.

\section{Referências}

CAPOVILLA, F.C.; RAPHAEL, W.D. Dicionário Enciclopédico ilustrado trilíngue da língua de sinais brasileira. v. 1 e v.2. São Paulo: EDUSP, 2001. 
João Pessoa, 2013. Dissertação da Universidade Federal da Paraíba.

COSTA, Messias Ramos. Proposta de modelo de Enciclopédia Visual Bilíngue Juvenil: Enciclolibras. Brasília, 2012. Dissertação da Unb (Universidade de Brasília).

MARINHO, Margot Latt. O ensino da biologia; o intérprete e a geração e sinais. Brasília, 2007. Dissertação da UnB (Universidade de Brasília).

MARINHO, Rosilene S. Neologismos em Libras: um estudo sobre a criação de termos na área de Química. Manaus, 2016. Dissertação da Universidade Federal do Amazonas.

OLIVEIRA, D.H. Fonética e fonologia. UFPB: João Pessoa, 2010. Disponível em: http://portal.virtual.ufpb.br/wordpress/wpcontent/uploads/2009/07/Fonetica_e_Fonologia.pdf>. Acesso em: 13 nov. 2012.

QUADROS, R. M.; KARNOPP, L. B. Língua de sinais: estudos linguísticos. Porto Alegre: ARTMED, 2004.

SAUSSURE, F. Curso de Linguística Geral. 28ª ed. São Paulo: Cultrix, 2012.

SOUSA, S.F.; SILVEIRA, H.E. Terminologias químicas em Libras: a utilização de Sinais na aprendizagem dos alunos surdos. Revista Química Nova na Escola. Vol. 33, N 1, fevereiro 2011. Disponível em: http://qnesc.sbq.org.br/online/qnesc33_1/06-PE6709.pdf Acesso em: 28 mar. 2014.

STUMPF, Marianne. Aprendizagem de Escrita de Língua de sinais pelo sistema SignWriting: Línguas de sinais no papel e no computador. Porto Alegre, 2005. Tese de Doutorado da Universidade Federal de Rio Grande do Sul.

INSTITUTO PHALA, Centro de desenvolvimento para surdos. Disponível:< https://www.youtube.com/watch?v=yoy9dGCvljY. >. Acesso em: Acesso em: 26 de setembro de 2014.

INSTITUTO FEDERAL FLUMINENSE - IFF, Vocabulário de Química em Libras - IFF. Disponível <https://www.youtube.com/watch?v=1LiRuhwSW74.> Acesso em: Acesso em: 26 de setembro de 2014.

UNEC - Centro Universitário de Caratinga, Glossário de LIBRAS para aula de Química. Disponível: <https://www.youtube.com/watch?v=spWR2dDSGGw.> Acesso em: 26 de setembro de 2014. 